\title{
Zugar de hija, lugar de madre Autoficción y legados familiares en la narrativa de hijas de desaparecidos en Argentina
}

Mariela Peller

\begin{abstract}
Resumen: En este artículo examino una serie de producciones de hijas de desaparecidos en Argentina. Los relatos ¿Quién te creés que sos? de Ángela Urondo Raboy (2012) y Aparecida de Marta Dillon (2015), y la instalación audiovisual Operación fracaso y el sonido recobrado de Albertina Carri (2015). Propongo que la experiencia de ser hija de desaparecidos y, luego, madre de nietos de desaparecidos, encuentra en la autoficción una forma de poder ser narrada y elaborada para sí y para otros. A partir de la experiencia de la propia maternidad, estas hijas despliegan un trabajo de narración y transmisión hacia las futuras generaciones, que supone una apertura hacia el futuro y una identificación con la propia madre. Ambas figuras de la madre, la madre-muerta y la hija-madre, se conforman como el motor de las obras. Escribir para saber, escribir como parte de un trabajo de duelo y también para transmitir y legar relatos a las futuras generaciones.

Palabras clave: Hijas de desaparecidos, maternidad, autoficción, posdictadura, Argentina, legados
\end{abstract}

\section{Place of daughter, place of mother. Autofiction and family legacies in the narrative of daughters of disappeared in Argentina}

\begin{abstract}
In this article, I will examine productions of daughters of disappeared in Argentina. The books ¿Quién te creés que sos? of Ángela Urondo Raboy (2012) and Aparecida of Marta Dillon (2015), and the audiovisual installation Operación fracaso y el sonido recobrado of Albertina Carri (2015). I will propose that the experience of being daughter of disappeared and mother of grandchildren of disappeared, have found in autofiction a way of being narrated and elaborated for herself and for others. From the experience of their own motherhood, these daughters do a working of narration and transmission to the future generations, which implies an opening to the future and also an identification with their own mothers. The figure of mother constitutes the engine of the work of these artists. Write to learn, write as part of a work of mourning and also to convey stories and legacies to the future generations.

Keywords: daughters of disappeared, motherhood, autofiction, post-dictatorship, Argentina, legacies
\end{abstract}

\section{Introducción}

Un día después de la muerte de su madre en octubre de 1977, Roland Barthes inicia un Diario de duelo (2009) en el que escribe: "Todo el mundo conjetura - así lo siento - el grado de intensidad de un duelo. Pero imposible (signos irrisorios, contradictorios) medir hasta qué punto alguien ha sido alcanzado" (p. 20). Y en una anotación realizada cinco meses después se refiere a la prisa que tiene por ponerse a trabajar en el libro sobre la fotografía, que será La cámara lúcida, prisa, escribe, por "integrar mi aflicción a una escritura" (p. 116). Me interesa comenzar por estas ideas presentes en el diario de Barthes, que anudan aflicción, duelo y escritura, porque contienen algunas de las claves interpretativas desde las que me interesa leer una serie de producciones estéticas de hijas de desaparecidos en Argentina. Se trata de las obras literarias ¿Quién te creés que sos? de Ángela Urondo Raboy (2012) y Aparecida de Marta Dillon (2015), y de la instalación audiovisual Operación fracaso y el sonido recobrado de Albertina Carri (2015).

En este ensayo propongo que estas obras, al igual que sucede con otras del universo de las producciones de hijas e hijos de militantes y/o desaparecidos en Argentina, reclaman una interpretación

${ }^{1}$ Socióloga y Doctora en Ciencias Sociales por la Universidad de Buenos Aires (UBA). Docente en la Carrera de Sociología, Facultad de Ciencias Sociales (UBA). Becaria Posdoctoral (CONICET) e investigadora del Instituto Interdisciplinario de Estudios de Género (Facultad de Filosofía y Letras, UBA).

E-mail: mariela_peller@hotmail.com 
desde la noción de autoficción. Como si algo se jugara allí en esa forma narrativa que se impuso como recurso a ser utilizado por las autoras/realizadoras. Las narraciones autoficcionales posibilitan un trabajo con la memoria y a la vez una apertura al presente, trabajan como lo hace la memoria, con fragmentos, restos, discontinuidades. Escribe Régine Robin sobre este tipo de escritura del yo: "Escritura trabajo de duelo, a la vez de deconstrucción de la ilusión biográfica y de reconstrucción, elaboración de un lugar distinto no aleatorio, lugar de verdad. Esta sería la tarea imposible de este objeto inasible que es la autoficción" (2002, p. 54. Resaltado en el original). ${ }^{2}$

Sostengo que la selección de la autoficción por parte de estas autoras se vincula con la experiencia de ser hijas de desaparecidos, que supuso una falta de saber sobre sus orígenes y sus filiaciones, un escamoteo de información que las condujo hacia una condición de búsqueda constante (de información, del cuerpo de los padres, de cierto saber sobre sí mismas y sus progenitores) y la consiguiente necesidad de elaboración de un trabajo de duelo (FREUD, 1993). Pero la autoficción también se impone frente a la necesidad que experimentan de transmitir su historia a otros. A la experiencia de ser hijas de desaparecidos se superpone la de ser madres de una tercera generación que ha llegado al mundo. Frente a esta nueva generación, las hijas ahora devenidas madres sienten la responsabilidad de legar un relato, un saber, una verdad, que ellas no poseen. La experiencia de ser hija de desaparecidos y, luego, madre de nietos de desaparecidos, encuentra en la autoficción una forma de poder ser escrita, narrada, elaborada para sí y para otros.

A partir de la novedad de la propia maternidad, estas hijas despliegan un trabajo de transmisión hacia las futuras generaciones, apertura hacia el futuro que requiere a su vez -como muestran las obras- de la identificación con la propia madre. En las obras analizadas la figura de la madre opera como articuladora de la construcción del sujeto de la enunciación. En los términos de Vanessa Vilches (2003) pueden ser entendidas como matergrafías, textos en los que la madre funciona como el Otro para quién, por quién y desde quién se estructuran los relatos. Particularmente, en las obras estudiadas la figura de la madre se encuentra duplicada. Representa tanto a las madres de las narradoras/realizadoras -ubicándose ellas en la posición de hijas- como a su propia condición de madres. Ambas figuras de la madre, la madre-muerta y la hija-madre, parecen ser el motor de estas obras. Escribir para saber, escribir como parte de un trabajo de duelo pero también para transmitir y legar relatos a las futuras generaciones. Tanto en las dedicatorias de los libros Aparecida y ¿Quién te creés que sos? como en el catálogo de la muestra Operación fracaso..., los hijos aparecen ocupando lugares centrales. Desplazar a sus progenitores del centro del relato y posicionarse ellas como sujetos de la enunciación les permite asumirse como madres de las nuevas generaciones, como aquellas que se encuentran en condiciones de producir un relato propio y trasmitirlo hacia el futuro. De esta manera, las obras se constituyen en símbolos histórico-culturales de la transmisión entre generaciones. En los términos de Jacques Hassoun (1996), las narradoras asumen una posición de "pasadoras" de relatos al inscribirse en una nueva genealogía para aportar a que las futuras generaciones sean partícipes de una "trasmisión lograda".

\footnotetext{
2 En su texto Régine Robin retoma parte de los planteos de Serge Doubrovsky, quien en su libro Fils (1977) puso por primera vez a circular la noción de autoficción.
} 


\section{Alutoficción y posdictadura}

Existen diversas periodizaciones sobre las narraciones relativas al pasado reciente argentino ya sea desde la historiografía, la literatura o la sociología (PITTALUGA, 2007; GAMERRO, 2015; CRENZEL, 2008). Más allá de las divergencias en la descripción de las etapas, hay cierto acuerdo sobre la existencia de una serie específica de narraciones compuesta por las producciones estéticas de la generación de los hijos de militantes y/o desaparecidos durante la última dictadura militar argentina (1976-1983). Son aquellas generaciones nacidas entre fines de los años sesenta y principios de los ochenta, quienes fueron niños ( $y$ en algunos casos adolescentes) en dictadura y que vivieron sus años de juventud en la posdictadura. Actualmente, estos jóvenes rondan los cuarenta años y han pasado a ser adultos que comienzan a tener hijos, que integran una nueva generación.

El comienzo de las intervenciones de esta "segunda generación" suele situarse en el año 1995 con el nacimiento de la agrupación HIJOS (Hijos e hijas por la Igualdad y la Justicia contra el Olvido y el Silencio), conformada por hijos de detenidos-desaparecidos. La agrupación estableció una discursividad estética como estrategia principal en sus operaciones políticas, entre las que se destacó la producción de escraches a los represores en el espacio público, con actividades callejeras y performáticas. Según Miguel Dalmaroni (2004) los escraches se organizaron alrededor de un registro de mezcla de estéticas y cruces de prácticas culturales (por ejemplo, a ciertas cuestiones vinculadas con los tonos serios de las épicas revolucionarias se le adicionaban elementos del estilo carnavalesco), que se encuentran presentes también en las revistas editadas por HIJOS.

La serie de producciones simbólicas, no todas vinculadas directamente con la agrupación HIJOS, es cada vez más extensa y se compone de una diversidad de registros, géneros e intervenciones: relatos literarios, films ficcionales y documentales, ensayos fotográficos, obras teatrales y performances. Estos jóvenes, afectados por el terrorismo de Estado, eligen al arte como vía privilegiada para indagar sobre el pasado de sus padres forjando un segmento de narrativas generacionales que pone el foco críticamente no sólo en la violencia catastrófica llevada adelante por la dictadura sino también en la organización de la vida cotidiana y en las opciones políticas y personales tomadas por la generación de sus padres. Jordana Blejmar y Natalia Fortuny (2013) señalan que más allá de su heterogeneidad y su dispersión, estas obras poseen algunas características comunes: configuran nuevos modos de entender la relación entre lo público y lo privado, entrecruzan los registros de la autobiografía con la ficción, se posicionan desde la interdisciplinariedad y conforman una memoria lúdica, desacralizada y no solemne. De esta manera, las obras consideradas han habilitado -tanto por su dimensión temática como formal- lecturas desde la categoría de posmemoria. ${ }^{3}$

Más allá de las diversas genealogías y características que se destacan de este segmento de narrativas generacionales, parece haber cierto acuerdo en que el film Los rubios de Albertina

\footnotetext{
${ }^{3}$ El término posmemoria surge a fines de los años 80 dentro de los estudios de la memoria para analizar artefactos culturales que trabajan sobre la perdurabilidad, la transmisión y la memoria de experiencias traumáticas a través de las distintas generaciones. Si bien la historia del término es breve, lo es más en la región latinoamericana (SZURMUK, 2009). Marianne Hirsch (1997) desarrolló dicha noción para referirse a la experiencia de la llamada "segunda generación", de aquellos sujetos que crecieron dominados por narrativas familiares de generaciones previas que se moldearon sobre eventos traumáticos, principalmente en el contexto de los sobrevivientes del Holocausto. La noción ha sido utilizada para analizar las experiencias de la generación de las hijas y los hijos de desaparecidos en Argentina y Latinoamérica (BLEJMAR Y FORTUNY, 2013; ROS, 2012). Sus usos en el contexto argentino han sido también discutidos por no referir de modo preciso a la experiencia de los hijos de desaparecidos (SARLO, 2005, PÉREZ, 2013).
} 
Carri (2003) marca un punto de ruptura y apertura en los modos en que los hijos de desaparecidos produjeron narraciones sobre el pasado reciente argentino. La ruptura generada por este documental subjetivo, documental-ficción o film autoficcional vendría dada principalmente por el tratamiento otorgado a la cuestión de la memoria y al uso de los testimonios. El film subvierte las formas tradicionales del género documental que procuraban la búsqueda de una verdad sobre los años setenta para focalizar, en cambio, en la exhibición de la filmación de la película y del equipo de trabajo, para hacer visible la ausencia y las ficciones de la memoria que conformaron la identidad de la realizadora como hija de desaparecidos. En su film, Carri se desplaza continuamente de la posición de hija a la que la han confinado diversos discursos para ubicarse en cambio como protagonista, cineasta, realizadora, integrante de un equipo de trabajo (GAMERRO, 2015; AGUILAR, 2006; LOGIE, 2015).

Más allá de las operaciones estéticas de vanguardia realizadas por Los rubios que condujeron a la crítica a asignarle una condición de quiebre respecto al pasado, me interesa pensar que algunas de las características de la película provienen de un movimiento más amplio, de un proceso general, que Alberto Giordano (2008) ha llamado "el giro autobiográfico". Si bien el autor focaliza su estudio en la literatura argentina contemporánea, identifica este giro como parte de una tendencia colectiva y de un movimiento de época que se desarrolla a nivel nacional y mundial en una diversidad de prácticas artísticas. Una tendencia por parte de los artistas a recurrir a la primera persona, a la rememoración y al registro de vivencias personales. Para Giordano, un texto bien logrado perteneciente a este fragmento de escrituras del yo, escaparía del "narcicismo y la autocomplacencia" para, en cambio, realizar "un ejercicio ético de autotransformación que en lugar de negar la fuerza de las particularidades subjetivas, las afirma menos para fortalecer la representación de lo privado que para tentar la experiencia singular de su descomposición" (GIORDANO, 2008, p. 39). En este tipo de prácticas, el escritor debe correr algún riesgo, el gesto de la escritura no puede ser gratuito para él, que debe, por el contrario, "dejarse conmover por la experiencia transformadora de lo íntimo" (p. 26). ${ }^{4}$ Cuestiones similares pero en un campo que excede a la literatura, habían sido planteadas por Leonor Arfuch (2007) en El espacio biográfico, donde se refería a la tendencia de la cultura contemporánea a la revalorización de la subjetividad y la proliferación de narrativas vivenciales en diferentes géneros y registros: entrevistas, conversaciones, relatos de autoayuda, historias, de vida, confesionarios, retratos, perfiles, entre otros.

El recorrido presentado hasta aquí quiere situar contextualmente las producciones estéticas de Urondo Raboy, Dillon y Carri en una zona donde se cruzan el campo de intervenciones de la generación de posdictadura con el campo de las obras del giro autobiográfico e intimista. En esa zona de intersección emerge la autoficción como recurso indispensable que permite la búsqueda de la propia identidad a través de la escritura, el desplazamiento de posiciones, la huida de la unicidad del relato para hurgar más bien en los fragmentos, las rupturas, las faltas, las discontinuidades, atendiendo no solo a la propia vida sino también al proceso de escritura en sí mismo (CORBATTA, 2009; Doubrovsky, 2012). Todas cuestiones que, como ya mencioné, estaban presentes en esa autoficción pionera que fue Los rubios. En efecto, no podemos dejar de señalar que la propia Carri cita en la película a Régine Robin, en una frase que afirma que

\footnotetext{
${ }^{4}$ La heterogeneidad entre lo íntimo y lo privado es fundamental en esta tendencia que Alberto Giordano denomina "giro autobiográfico" y que, como él mismo afirma tomando prestada la denominación de Daniel Link, también podría denominarse "giro intimista" (GIORDANO, 2008, p.46).
} 
la necesidad de justificar una identidad surge cuando ésta se ve amenazada. Para Robin (1994), una autoficción se produce cuando un texto pone en escena la imposibilidad de la narración misma, cuando el artista sin dejar de narrarse a sí mismo, es consciente de la parte de ilusión que produce en la narración de sí. Una autoficción sería una autobiografía consciente de su propia imposibilidad. El prólogo de ¿Quién te creés que sos? se refiere a estas cuestiones. Así describe Ángela Urondo Raboy a su libro:

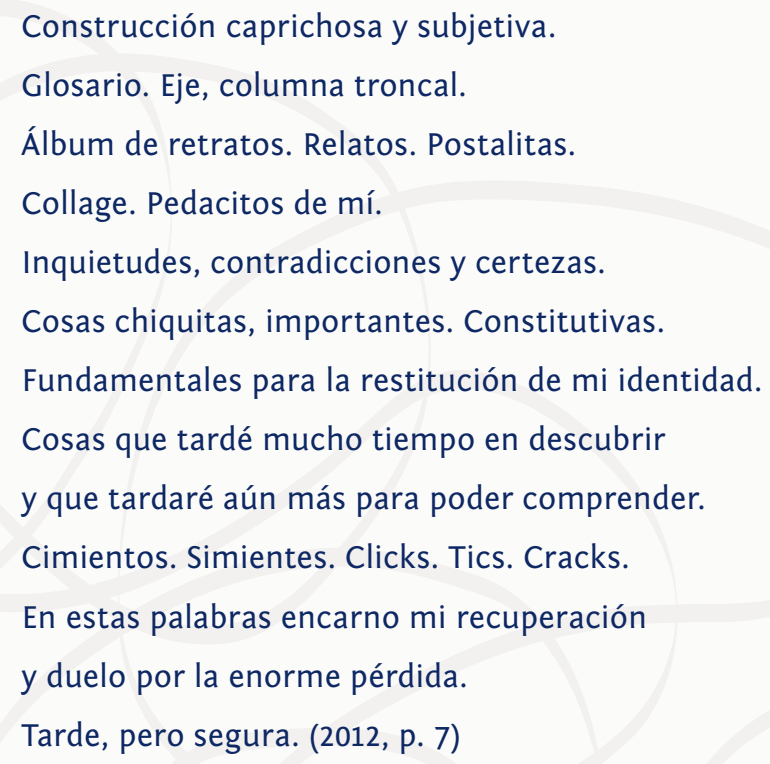

\title{
Matergrafías
}

Vanessa Vilches sostiene que la mater - figura discursiva que refiere a la madre - se desempeña como generadora del texto autobiográfico debido a la importancia que adquiere la madre como primer oído del sujeto, como primer otro significativo. La escritura autobiográfica no sería otra cosa que la búsqueda del cuerpo materno que se ha perdido. Decir "yo soy" sería escribir el duelo por ese objeto perdido. Por su parte, Nora Domínguez (2016) en un estudio sobre escritoras contemporáneas propone un modelo de análisis que piensa lo materno como una experiencia, una dimensión que pone en contacto cuerpos y palabras de madres e hijas, que hacen circular sentidos y afectos novedosos.

\begin{abstract}
Cuando los hijos o hijas se constituyen en voceros de las historias maternas, se instala la posibilidad de convertir el saldo generacional tanto en un ajuste de cuentas con el pasado de los padres como en la afirmación de una identidad narrativa propia. Frente a un presente de muertos, los relatos abren vías para la ficción que ensayan respuestas singulares al trabajo con los legados familiares.
\end{abstract} (DOMINGUEZ, 2016, p. 41)

En las obras de Urondo Raboy, Dillon y Carri la pérdida del cuerpo materno tiene una materialidad significativa porque no se trata solamente de una pérdida experimentada a nivel simbólico sino a nivel real. En los tres casos se trata de hijas de militantes desaparecidos que 
pertenecieron a la organización político-militar Montoneros y que fueron secuestrados y asesinados por la dictadura militar argentina en los años setenta. En otras palabras, la centralidad en los relatos de la figura del cuerpo materno es elección de los textos pero es también el resultado de la desaparición que de ese cuerpo hicieron los militares durante los años del terrorismo de Estado. La figura del cuerpo de los desaparecidos ha jugado un papel indispensable en las estrategias de representación de los desaparecidos en Argentina (LONGONI, 2010).

El libro de Ángela Urondo Raboy fue en un primer momento un blog personal, llamado Pedacitos. La historia de Ángela es bien compleja: en junio de 1976 en Mendoza, cuando Ángela tenía sólo 11 meses de edad, fueron emboscados por las fuerzas represivas en el auto en el que viajaban los tres. La madre (Alicia Cora Raboy) está desaparecida, el padre (Francisco "Paco" Urondo) fue asesinado en el momento y ella fue secuestrada y llevada a un orfanato del que la recuperó su abuela materna. Pero la historia no termina allí. La familia materna decide darla en adopción a una prima de la madre desaparecida y perder todo contacto con la familia Urondo; recién a los 20 años, Ángela conoce su historia familiar y comienza una travesía para restituir su identidad, que implicó un juicio de des-adopción finalizado a comienzos de 2013, una figura legalmente inexistente, pues las adopciones plenas son inapelables.

Aparecida de Marta Dillon comienza su relato en el año 2010, el día en que la autora se entera de que ha aparecido el cuerpo de su madre desaparecida por más de 30 años. Es el cuerpo de la madre que aparece el que pone el relato en movimiento. Marta Taboada se encontraba desaparecida desde octubre de 1976, cuando había sido secuestrada de su domicilio.

En términos genéricos estas obras presentan similitudes. Son una mezcla de crónica, diario íntimo, autobiografía, biografía, relato, investigación documental. Como ya señalé, creo que es indispensable trabajarlas a partir de la noción de autoficción, tal como la entiende Régine Robin (1994, p. 22). Porque son escrituras que subvierten las distinciones más clásicas entre lo público y lo privado, lo político y lo personal, para dar cuenta de las herencias y las filiaciones. Presentan estructuras fragmentarias, que incluyen junto a los momentos más narrativos y ensayísticos, descripciones de fotografías, poemas, sueños, fantasías, documentos, actas judiciales. Se trata de textos que construyen pactos de lectura ambiguos, que, si bien se elaboran con procedimientos ficcionales, trazan también líneas que permiten identificar por medio del nombre propio a la autora, a la narradora y al personaje. Son relatos que no se pretenden verídicos pero que no obstante llevan marcas de autenticidad.

Por su parte, Operación fracaso y el sonido recobrado instalación audiovisual de Albertina Carri (2015) supone la vuelta de la artista hacia tópicos que ya había trabajado en su film Los rubios. Los modos en que ficción y realidad se entrelazan para construir memorias sobre los desaparecidos, la influencia que tanto la ausencia como los relatos heroicos sobre la militancia de sus padres han ejercido sobre ella y su identidad, cómo la ficción opera en los relatos que ella ha contribuido a forjar sobre sí misma y sus padres. En el libro sobre la película documental, Los rubios. Cartografía de una película, Carri escribía: “No hay modo de desprenderse de los recuerdos, sólo los puedo reinventar, redefinir, releer. Pero ahí estarán confirmando la ausencia para siempre" (2007, p. 10). La instalación retorna sobre esas cuestiones y nuevamente se afirma en pensar el pasado desde el presente. En investigarse a sí misma como cineasta, como artista, sin sustraerse de pensar los legados y los modos en que las obras de su padre (las investigaciones 
sociológicas de Roberto Carri) y de su madre (las cartas que escribiera desde el cautiverio Ana María Caruso) se vinculan con quien es Albertina hoy.

En cuanto a las modulaciones de estas obras, a diferencia de otras elaboradas por la generación de los hijos en las que predomina la ironía, la parodia, el sarcasmo o hasta la risa (KOHAN, 2014; GAMERRO, 2015; GATTI, 2011; ARFUCH, 2015), los relatos de Urondo Raboy y Dillon, y la instalación de Carri -principalmente en la zona dedicada a la madre- se sostienen sobre la tonalidad nostálgica de la perdida de la madre, de la añoranza por el cuerpo materno: su leche, sus abrazos, su olor, su ropa, su voz, su palabra. A este tono nostálgico lo acompañan como contrapunto constantes referencias a la vida, a la felicidad, al futuro. Tonos que refieren a esas dos figuras de la madre que organizan los relatos. La madre perdida y la madre presente, esa que ellas son ahora. Estas hijas-madres no tienen otra tarea que, como sostiene Urondo Raboy, inventar palabras nuevas sobre lo ocurrido para legar a sus hijos: "Palabras que habremos de inventar si queremos decir algo nuevo, algo propio sobre lo que nos pasó, sobre lo que no nos ha dejado de pasar" (URONDO RABOY, 2012, p. 262).

Posición de hijas, posición de madres, posición de "pasadoras" de relatos. En estas obras autoficcionales el deseo de saber quiénes fueron sus madres se yuxtapone con el deseo de saber sobre sí mismas: ¿Quién es mi mamá? ¿Quién soy yo? La respuesta no puede darse separadamente. Para poder contestar la pregunta sobre su propia identidad las autoras necesitaban poder responderla respecto de la madre. Las obras dedican buena parte a la historia de esa relación, a los pocos años juntas y a los muchos separadas. Desde un presente que tiene a las hijas como adultas, el relato se desplaza hacia el pasado nostálgico de la infancia, cuando madre e hija estuvieron juntas. Cuando sus cuerpos se tocaron. Para retornar luego a este presente que en el que son madres que intentan dar sentido a un relato posible de ser trasmitido a sus propios hijos.

\section{Nostalgia de su cuerpo}

Aparecida relata los avatares y los modos de tramitar la aparición del cuerpo de Marta Taboada, madre de Marta Dillon, desaparecida desde 1976, cuando su hija tenía 10 años. La narración comienza el día en que Dillon recibe el llamado de Antropólogos Forenses para comunicarle que han encontrado el cuerpo de su madre. ${ }^{5} \mathrm{Y}$ desde ese presente que es la aparición se mueve hacia el pasado y hacia el futuro.

El cuerpo en ese momento en que aparece es huesos. "Los huesos de mamá", escribe Dillon, para referirse al hallazgo. Sobre esos huesos construye una prosa poética, donde los huesos de su madre se confunden con los suyos. Los huesos de su madre son sus huesos:

¿La encontraron? ¿Qué habían encontrado de ella? ¿Para qué quería yo sus huesos? Porque yo los quería. Quería su cuerpo. De huesos empecé a hablar más tarde, frente a la evidencia de unos cuantos palos secos y amarillos iguales a los

\footnotetext{
5 El Equipo Argentino de Antropología Forense es una institución reconocida mundialmente, cuyos servicios son solicitados por diversos países. El equipo realiza, junto con Madres de Plaza de Mayo y Abuelas de Plaza de Mayo, una tarea de búsqueda y recuperación de los restos de desaparecidos y asesinados que fueran enterrados en fosas comunes o tumbas NN. La recuperación de los restos - de los huesos -, en los casos en que se logra su individualización, permite a los deudos culminar el duelo y darles humana sepultura.
} 
de cualquiera. Iguales a esos que se enhebran con alambre y los alumnos manipulan como utilería en un aula de biología. Esquirlas de vida. Destello marfil que desnudan las aves de carroña a campo abierto. Ahí donde se llega cuando se va a fondo, hasta el hueso. Lo que queda cuando todo lo que en el cuerpo sigue acompañando al tiempo se ha detenido, la hinchazón de los gases, el goteo de los fluidos, el banquete de la fauna cadavérica, el ir y venir de los últimos insectos. Después, los huesos. Chasquido de huesos, bolsa de huesos, huesos descarnados sin nada que sostener, ni un dolor que albergar. Como si me debieran un abrazo. Como si fueran míos. Los había buscado, los había esperado. Los quería. (DILLON, 2015, p. 33)

El cuerpo como zona de identificación entre madre e hija, como espacio de inscripción de la herencia pero también como ese territorio nostálgico al que es necesario volver y no se puede: "la inconmensurable nostalgia de su cuerpo abrazando los nuestros" (p. 82). El cuerpo como figura a partir de la cual tejer paralelismos entre madre e hija: identificaciones, diferencias, herencias. Al comienzo del libro asistimos a la descripción de una fotografía en la que están las dos juntas en la playa. "¿Qué edad hay que tener para que el antebrazo de tu madre tenga la exacta medida de tu torso?" (p. 11). Y más adelante compara su propia maternidad con la de su madre, situándose como heredera de un modo de ejercer la maternidad en el que los cuerpos son la cifra:

\footnotetext{
Mi maternidad es cuerpo a cuerpo. El aliento de las mañanas, el sudor de las noches, sus babas en los bocados que no engullen, la sangre en las rodillas, las migas entre las sábanas, las lagañas, los mocos; las cosquillas y las luchas. El lenguaje del amor no se habla, se inscribe. Esa poesía material es la que aprendí de mi madre. (p. 49)
}

La descripción de las ropas es otra forma de situar el cuerpo y la identidad de la madre en el centro del relato. Lorena Amaro (2009) ha destacado como la ropa suele ocupar lugares privilegiados en las escrituras autobiográficas porque remiten a los vínculos entre cuerpo, vestuario e identidad. Representan modos de relacionarse con el propio cuerpo y con los otros. Remiten a marcas de identidad sexual y de clase, entre otras. Las ropas de la madre aparecen en al menos tres escenas de Aparecida. En la primera, una compañera de cautiverio de la madre le cuenta que cuando estaban secuestradas en verano Marta Taboada (la madre de Marta Dillon) cortó las mangas de una polera e hizo lo mismo con la ropa de otras compañeras. La segunda escena refiere a los recuerdos que tiene Dillon de la ropa que usaba su madre cuando ella era niña, una pollera escocesa sobre la que durmió en un viaje en auto, una campera de colores que no logró encontrar nunca más. Y una tercera escena que refiere a los restos de ropas destruidas que acompañan a los huesos encontrados de Marta Taboada, de los que no puede saberse con certeza si pertenecían a ella o no pero que la hija especula sobre su propiedad, como es el caso de una ropa interior de color negro, sobre la que tiene un recuerdo de infancia.

La figura del cuerpo de la madre cobra varias funciones en el relato. Como cuerpo aparecido representa la posibilidad del duelo, si bien la narradora critica la hipótesis de que tener el cuerpo habilita la posibilidad del duelo, su propio texto es la prueba de que la presencia material de 
esos huesos ha generado la apertura hacia algo novedoso. Por otro lado, el cuerpo es también la figura a través de la que Dillon se identifica con su madre. Las unen sus maternidades que se caracterizan por implicar el cuerpo. Las une también el nombre que poseen en común: Marta.

Sobre el nombre en común, casi al comienzo del libro, Dillon relata una anécdota que refuerza la identificación entre madre e hija que el texto produce por medio de los cuerpos: parece que madre e hija también tienen un aspecto corporal en común. En 1996, cuando Dillon tenía 30 años (casi la misma edad que su madre cuando desapareció) se encontró en un bar con una compañera de cautiverio de su madre. Cuando la vio entrar la señora le dijo:

-Te parecés a Marta, ¿no?

-Yo soy Marta

Esa anécdota que Dillon elige narrar refuerza la identificación entre madre e hija, porque lo interesante de la confusión es que ambas afirmaciones son ciertas. Por medio de esa confusión el yo de la narración se configura en una relación constante con el cuerpo de la madre. La comparación entre sus maternidades, la identificación entre sus cuerpos y entre sus modos de dar afecto, se construye en el texto a partir de evocaciones y recuerdos, que Dillon narra sobre las características de la maternidad de su madre. Descripciones de Marta Taboada en su día a día, descripciones de las formas en que ejercía el cuidado de sus hijos, descripciones que remiten a esa "maternidad cuerpo a cuerpo", que es también la modalidad de maternidad que Dillon escoge para figurarse a sí misma. La narración mantiene, así, la tensión de la anécdota en la que se confunden (y se funden) los nombres y las apariencias corporales de madre e hija.

\section{Soy mi madre}

El libro de Urondo Raboy es ecléctico, fragmentario, derivas que posee por haber sido en primer término entradas de un blog. Ese eclecticismo, esa fragmentariedad es parte de la misma historia de Ángela. Discontinuidad, secretos, mentiras, saberes escamoteados. Retazos, pedacitos, fueron lo que ella tuvo en un comienzo para empezar a armar su historia. El libro evoca en su composición la (re)construcción de una identidad. Porque funciona como lo hace la memoria: intentando unir los pedazos de una historia mal contada a través de materiales heterogéneos.

El texto reflexiona sobre la niña Ángela en distintas situaciones de su vida. Piensa su período en cautiverio asumiéndose bajo la figura de una niña ex detenida desaparecida y lanza un incómodo reclamo al Estado: ¿acaso los niños, por no haber sido blanco directo del exterminio, no merecen el reconocimiento de prisioneros políticos? También rememora la etapa en la que fue una beba hija de militantes para comprender qué implicancias tuvo Montoneros en el trágico desenlace. Urondo fue acusado de tener una relación con Alicia Raboy mientras vivía con Lili Massaferro y, tras un Juicio Moral Revolucionario, fue sacado del diario Noticias, degradado y trasladado a Mendoza, donde quedaba más expuesto. La infidelidad no entraba dentro de los marcos morales del idealizado hombre nuevo. Ángela descubre que la desprotección se fue 
haciendo presente entre los militantes y sus familias, ante una organización que aún hoy sigue sin asumir su responsabilidad, varada en la figura del héroe mártir.

Pero Ángela se corre también del lugar de niña para pensarse desde su posición de madre. Como sucedía en el libro de Dillon, ¿Quién te creés que sos? está dedicado a sus hijos: Boris y Rufino. Ellos son el motor de su búsqueda por saber sobre su propia historia. ¿Cómo contarles a sus hijos la historia de sus abuelos, y principalmente de su abuela, si ella misma no la conocía? Sus hijos instalaron la necesidad de saber más. Es para ellos que Ángela crea formas nuevas de contar lo que pasó. Ese pasaje del relato de una generación a la otra se llama transmisión. Así, Ángela, la adulta, la madre, se coloca como aquella que desea trasmitir adecuadamente la historia. ¿Podemos imaginar una tarea más éticamente acorde para esta adulta a quien de niña su identidad le fue obliterada?

El libro se compone de tres partes diferenciadas: "Documentos (palabras inapelables)", "Crónicas (palabras hacia afuera)" y "Conclusiones (palabras interiores)". Se agrupan así diferentes tipos de texto. La primera parte incluye fotografías, cartas, textos escritos por otros, testimonios, notas periodísticas y el fallo de la sentencia del caso de asesinato de su padre y secuestro y desaparición de su madre. La segunda es la más ensayística, Ángela narra sus diversos viajes a Mendoza, su infancia con su familia adoptiva, el proceso de recuperación de su identidad, la búsqueda de datos sobre su madre, sus días pasados ella misma en cautiverio, entre otras cuestiones sobre las que reflexiona de modo crítico. Finalmente, en la tercera parte más ficcional, nos acerca poemas, sueños, imaginaciones, recuerdos. Es en esta última parte, más personal y emotiva, donde la figura de su madre cobra más fuerza.

Allí nos encontramos con algunos poemas que tienen a la madre como protagonista: "Matria" o "Incognita". También con los recuerdos de Ángela sobre los brazos de su madre, sobre su último contacto corporal: "Recuerdo el último contacto, cuerpo a cuerpo, que no llegó a ser abrazo ni beso ni despedida, apenas una brusca sobrevida. Recuerdo la voz de su mirada, su olor y su miedo" (URONDO RABOY, 2012, p. 198). En esta tercera parte aparecen otros dos textos sobre los que quiero focalizar, que parecen entradas de un diario íntimo. Me interesan particularmente porque creo que ellos reflejan el modo en que la narradora entiende que la relación con su madre ha sido configuradora de su propia vida.

En "Inconclusiones" (p. 213) Ángela sostiene que "nunca supo terminar nada” e sugiere que esa modalidad de hacer, esa constancia en las inconclusiones está determinada por esa primera historia sin final que fue la de su madre ("secuestrada frente a mis ojos, desaparecida para siempre”). Pero también cree que la despedida que está realizando al escribir ese texto le servirá para comenzar a concluir: "Soy mi madre que aún me abraza. Conservo su calor para siempre conmigo, haciéndome menos huérfana" (p. 216).

Por otra parte, en "Cumplir vida" (p. 263) se expresa con claridad la modificación en la posición subjetiva que experimentan estas hijas cuando comienzan a ocupar también el lugar de madres. Escribe Ángela:

Cada año me pregunto: ¿qué es cumplir años? ¿Cumplir con qué? ¿Cumplir con la vida, por no haber muerto, durante un año más? ¿Qué festejamos, el hecho de seguir viviendo? Prefiero pensar que se trata de rememorar el día en que se comenzó a vivir fuera de la madre. Re-unirse en torno a ese hecho, compartir 
la vivencia, transmitirla, establecer la memoria de ese comienzo, que pertenece tanto a la madre como al hijo. (Cuando no se tiene la mamá, el cumpleaños pierde la mitad del sentido.) Para mí, pasó a ser un ritual para la sociedad, para los otros. Interiormente, mis cumpleaños siempre fueron ella y yo. Yo, sin ella, frente al espejo del baño, diciéndole a los ojos: “Feliz cumpleaños, gracias por darme la vida, lo hicimos, un año más", como si conservar mi propia vida fuera conservar de algún modo también la suya, y ése fue siempre mi compromiso con ella, año a año, y dentro de unos días, uno más. Ahora que tengo hijos, mi compromiso se renueva con ellos, y el festejo vuelve a tener sentido, porque ellos no estarían acá si yo no hubiese sobrevivido todos estos años. Ahora, mis cumpleaños son de mamá, de mis hijitos y mío, y el compromiso es con ellos, para que nunca les falte su mamá, su historia, su festejo. (URONDO RABOY, 2012, p. 263)

La figura de la madre cumple en la narración de Urondo Raboy diversas funciones: motor de la escritura, espacio de posibilidad de conformar un saber sobre sí misma, territorio nostálgico y de identificación de cuerpos femeninos. La autora, dedica gran parte de su libro a comprender y descubrir quién era su madre, Alicia Cora Raboy, periodista del diario Noticias. Ángela destaca que la historia de Alicia fue silenciada si se la contrasta con el conocimiento que se tiene de la figura pública de su padre, el poeta Francisco "Paco" Urondo. Y subraya esa necesidad de saber más sobre la madre una y otra vez. Refiriéndose a esa búsqueda afirma en una entrevista: "Estoy descubriendo a una tipa interesantísima y cuanto más la conozco más me gusta. Es muy, muy extraño enamorarse de la propia madre" (ENRIQUEZ, 2013). Este "enamorarse" es también recuperarse a sí misma como hija de Alicia. Filiación que no se refiere solamente a conocer la historia de su madre sino también a la posibilidad legal de llevar el apellido de sus padres biológicos y poder darle así ese apellido también a sus propios hijos.

\section{Lengua común}

Operación fracaso y el sonido recobrado, instalación audiovisual de Albertina Carri, se desplegó en la sala PAyS en el Parque de la Memoria en la Ciudad de Buenos Aires entre septiembre y noviembre de 2015. Es preciso señalar que a la muestra se accede tras recorrer el Monumento a las Víctimas del Terrorismo de Estado, pieza que despliega en un muro los nombres de miles y miles de detenidos-desaparecidos y/o asesinados durante la última dictadura militar argentina. Un sendero en forma de herida que va sumando nombres y que espera por la aparición de los 30.000 desaparecidos.

Como mencioné más arriba, Carri vuelve en esta obra a algunos de los tópicos trabajados en Los rubios. Pero se trata de un regreso descentrado. Porque la posición de Carri ahora es otra. Más de diez años después del estreno de su film documental, Carri continúa releyendo y reinventando los recuerdos del pasado desde un presente que la encuentra modificada. No solo el tiempo ha pasado. Algo cambió en su vida. Ella tuvo un hijo. Hoy es madre y tiene más años que los que tenían sus padres cuando desaparecieron. Su mirada actual está atravesada 
por su maternidad, por su crecimiento, por el tiempo transcurrido. Carri escribe en el catálogo de la muestra:

Los ríos de la memoria no siempre son caudalosos, pero aunque corra una pequeña línea de agua por su lecho, ella es tan obstinada, que modificará la tierra por la que pasa, aunque tan solo sea por el paso del tiempo mismo. Quiero ser ese lecho, quiero ser esa tierra, quiero contarle al mundo sobre ese poder que tiene el hecho de estar acá y seguir recordando (CARRI, 2015, p. 4)

La instalación juega a tender puentes entre pasado y presente a través de cuatro espacios que conforman un diálogo entre las producciones de Albertina Carri, Roberto Carri y Ana María Caruso. Investigación del cuatrerismo, Cine puro, Allegro- A piacere y Punto impropio. Si el documental autoficcional Los rubios finalizaba con el tema musical "Influencia" de Charly García, es a partir de ese mismo tema que podemos decir empieza Operación fracaso.... Obra que exhibe la persistencia de las influencias del pasado en las obras del presente y que refiere a la posición ambigua de un sujeto ante su herencia. Ambigüedad que se expresa en el deseo y la imposibilidad de sustraerse de los legados de las generaciones precedentes. Dice el tema de Charly García:

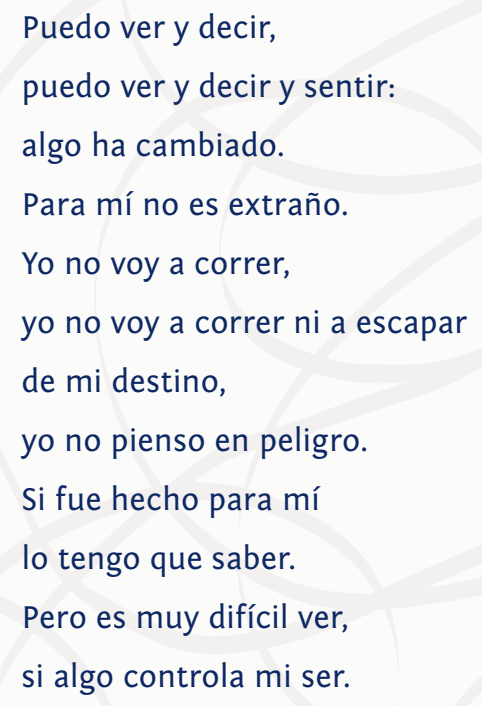

Investigación del cuatrerismo es el espacio del padre. A partir del primer libro escrito por Roberto Carri, Isidro Velázquez. Formas pre-revolucionarias de la violencia (1968), Albertina emprende una investigación para realizar una película sobre el caudillo que nunca llegó a terminar. La instalación muestra en cinco pantallas de televisión imágenes de archivo de la investigación mientras una actriz le da voz a Albertina narrando los avatares de la investigación y la escritura de múltiples y fallidos guiones. El relato nos habla no solo sobre el recorrido realizado por la artista en búsqueda de las motivaciones del padre para escribir su obra sobre Velázquez sino también de su intención por comprender las formas en que el legado del padre influye aún hoy sobre sus propias producciones.

Punto impropio es el espacio dedicado a la obra de la madre, quizás el más emotivo de la instalación. Carri vuelve una vez más a las cartas que su madre les escribiera a ella y a sus hermanas mientras estuvo en cautiverio, pero ahora lo hace como una hija que es también 
madre. "Esas cartas -dice Albertina- son el libro que Ana María Caruso no pudo escribir", son a su manera una obra como la de Roberto Carri. Obra materna que Albertina quiere rescatar y revalorar. Porque como sucedía en el caso de Alicia Raboy, la madre de Ángela Urondo Raboy, la obra de Ana María Caruso, profesora de literatura, siempre quedó subvalorada frente a la figura pública del intelectual que fue Roberto Carri.

En una sala oscura observamos sentados un punto luminoso con imágenes en loop y un nombre de mujer que se despliega a su alrededor: ANA MARIA. Desde una "pura lengua del afecto", como la llamó Ana Amado (2009, p. 195), las cartas contienen consejos sobre la vida cotidiana de las niñas, recomendaciones de obras literarias, preocupaciones por las amistades, demandas para que realicen actividades deportivas, inquietudes sobre la alimentación, entre muchas otras cuestiones. Fiel a la letra, Albertina le pone voz a las cartas de su madre y lee:

\footnotetext{
Querida Albertina. Dos puntos. Tus dibujos son muy lindos. Punto. Signo de interrogación. Cómo estás. Cierra signo de interrogación. Abre signo de interrogación. Qué tal tus amigos Juan y Vanesa. Cierra signo de interrogación. Espero que juegues mucho y que el colegio que es muy lindo de guste. Punto. Portate bien. Punto (CARRI, 2015).
}

Escuchando a Albertina leyendo las cartas escritas por su mamá, Ana María Caruso, nos convertimos en partícipes de la complicidad de una lengua común entre las mujeres de esas dos generaciones. Esa lengua de las madres que es también su obra.

Cine puro es la zona del cine como materia. Un espacio que experimenta con los rollos de cintas de celuloide, con los efectos que el paso del tiempo produce sobre esa materialidad, con la forma artística que esos materiales puede adquirir en el presente. Durante el proceso de investigación de archivo aparece una lata olvidada por mucho tiempo en un galpón, esa cinta contiene imágenes que ya no pueden distinguirse, que son manchas que convocan a producir una trama propia. Cine puro realiza un homenaje a las películas militantes de las décadas del sesenta y setenta, que, como algunos de sus directores, continúan desaparecidas.

El espacio compartido por A piacere y Allegro es el espacio del sonido y del "PRESENTE", como indican las tipografías en la pared del fondo de la sala. En $A$ piacere, es el espectador quien enciende los proyectores antiguos para producir libremente ciertos sonidos, que Albertina Carri compara con la sensación de estar en el vientre materno. Allegro, por su parte, pone a funcionar máquinas de proyectar sin películas, para que escuchemos el sonido del cine, para que oigamos el ritmo rápido y vertiginoso generado por la ausencia de cinta, que pone en evidencia la materialidad pura -el hardware como escribe Carri- de la proyección del cine.

La intertextualidad entre las obras de los Carri-Caruso, desplegada por Operación fracaso y el sonido recobrado es un nuevo mojón en ese diario de duelo que es la obra de Albertina Carri. La obra de Carri, como las palabras de Roland Barthes - citadas al comienzo de este ensayo -, refiere a esa capacidad infinita que posee la muerte y la ausencia de los seres queridos de interpelar al sujeto.

En las obras de Carri, Dillon y Urondo Raboy las narradoras/realizadoras asumen al menos tres posiciones: la de hijas, la de madres y la de pasadoras de relatos entre generaciones. Para poder generar un relato pasible de ser transmitido a las futuras generaciones, primero 
necesitaron conocer su propio pasado, narrarse su propia vida aun siendo conscientes de la imposibilidad de que ese relato sea cerrado y conclusivo. La autoficción como forma narrativa les permite sostener esa tensión entre necesidad e imposibilidad.

Si bien la posibilidad - subjetiva e histórica - de la construcción de ciertas narraciones sobre los acontecimientos vividos durante los años de violencia política en Argentina es el resultado de las modificaciones ocurridas en los discursos sociales referidos a la memoria del terrorismo de Estado, en estas obras esa apertura parece verse reforzada por la necesidad que como madres se les plantea a estas artistas de transmitir las herencias, legar relatos simbólicos y construir memorias para las nuevas generaciones que ya han arribado a la escena familiar y social. El advenimiento al mundo de los nietos de desaparecidos, confronta a las hijas con su posición subjetiva de madres, ubicándolas frente al deber ético-político de hacer con su pasado y el de sus antepasados, para poder "pasar" la historia. Las obras se constituyen en símbolo cultural de la transmisión entre generaciones, porque intentan inscribirse a sí mismas en una genealogía para aportar a que las futuras generaciones sean partícipes de un "pasaje logrado o transmisión lograda" (HASSOUN, 1996).

\section{Referencias}

AGUILAR, G. Otros mundos: un ensayo sobre el nuevo cine argentino. Buenos Aires: Santiago Arcos Editor, 2006.

AMADO, A. La imagen justa. Cine argentino y política. 1980-2007. Buenos Aires: Colihue, 2009.

AMARO, L. Vida y escritura. Teoría y práctica de la autobiografía. Santiago de Chile: Ediciones Universidad Católica d Chile, 2009.

ARFUCH, L. "Memoria, testimonio, autoficción. Narrativas de infancia en dictadura". Kamchatka. Revista de análisis cultural, Valencia, n.6, p. 817- 834, 2015.

ARFUCH, L. El espacio biográfico. Dilemas de la subjetividad contemporánea. Buenos Aires: FCE, 2007.

BARTHES, R. Diario de duelo. México: Siglo XXI, 2009.

BLEJMAR, J.; FORTUNY, N. (Org.) "Introduction”, dossier: "Revisiting postmemory: The intergenerational transmission of trauma in post-dictatorship Latin American culture". Journal of Romance Studies, Liverpool, v. 13, n 3, p. 1-5, 2013

CARRI, A. Los rubios. Cartografía de una película. Buenos Aires: BAFICl/ Gobierno de la Ciudad de Buenos Aires, 2007.

CORBATTA, J. Psicoanálisis y literatura: La auto-ficción. In: VII Congreso Internacional Orbis Tertius de Teoría y Crítica Literaria, 2009, La Plata: FAHCE. Disponible en: <http://www.memoria.fahce.unlp.edu.ar/trab_eventos/ev.3529/ev.3529.pdf〉. Acceso: 01/09/2016

CRENZEL, E. La historia política del Nunca más. Buenos Aires: Siglo XXI, 2008.

DALMARONI, M. La palabra justa. Literatura, crítica y memoria en la Argentina, 1960-2002. Mar del Plata: Melusina, 2004.

DILLON, M. Aparecida. Buenos Aires: Sudamericana, 2015 
DOMINGUEZ, N. "Lengua-cuerpo-madre: una relación problemática entre las escritoras contemporáneas argentinas". In: PUBILL, C. y BRIGNOLE, F. (eds.) Miradas desobedientes. María Teresa Andruetto ante la crítica. Valencia: Albabros, 2016.

DOUBROVSKY, S. Fils. Paris: Gallimard, 1977

DOUBROVSKY, S. "Autobiografía / verdad /psicoanálisis". In: CASAS, A. (ed.) La autoficción. Reflexiones teóricas. Madrid: Arco, 2012.

ENRIQUEZ, M. “Caer no es caer”. Suplemento Radar, diario Página 12, febrero de 2013.

FREUD, S. "Duelo y melancolía". In: FREUD, S. Obras completas. Tomo XIV, Buenos Aires: Amorrortu, 1993.

GAMERRO, C. Facundo o Martín Fierro, Los libros que inventaron la Argentina. Buenos Aires: Sudamericana, 2015.

GATTI, G. Identidades desaparecidas. Peleas por el sentido en los mundos de la desaparición forzada. Buenos Aires: Prometeo, 2011.

GIORDANO, A. El giro autobiográfico de la literatura argentina actual. Buenos Aires: Mansalva, 2008.

HASSOUN, J. Los contrabandistas de la memoria. Buenos Aires: Ediciones de la Flor, 1996.

HIRSCH, M. Family Frames: Photography, Narrative and Postmemory. Cambridge/ Londres: Harvard University Press, 1997.

KOHAN, M. "Pero bailamos", Katatay. Revista de crítica literaria latinoamericana. La Plata, año IX, n. 11/12, p. 23-27, 2014.

LOGIE, I. "Más allá del paradigma de la memoria: la autoficción en la reciente producción posdictatorial argentina: El caso de 76 (Félix Bruzzone)". Pasavento. Revista de estudios hispánicos, Madrid, n.5, 2015.

LONGONI, A. Fotos y siluetas: dos estrategias contrastantes en la representación de los desaparecidos. Buenos Aires: Biblos, 2010.

PÉREZ, M. E. "Their lives after: Theatre as testimony and the so-called 'second generation' in post-dictatorship Argentina”. Journal of Romance Studies, Liverpool, v. 13, n 3, p. 6-16, 2013.

PITTALUGA, R. "Miradas sobre el pasado reciente argentino. Las escrituras en torno a la militancia setentista (1983- 2005)". In: FRANCO, M. y LEVIN, F. (comp.), Historia reciente. Perspectivas y desafíos para un campo en construcción. Buenos Aires: Paidós, 2007.

ROBIN, R. “La autoficción. El sujeto siempre en falta”. In: ARFUCH, L. Identidades, sujetos y subjetividades. Buenos Aires: Prometeo, 2002.

ROBIN, R. Identidad, memoria y relato. La imposible narración de sí mismo. Buenos Aires: UBA, 1994.

ROS, A. The Post-dictatorship Generation in Argentina, Chile, and Uruguay. Collective Memory and Cultural Production. New York: Palgrave MacMillan, 2012.

SARLO, B. Tiempo pasado. Cultura de la memoria y giro subjetivo de una discusión. Buenos Aires: Siglo XXI, 2005. 
SZURMUK, M. “Posmemoria”. In: SZURMUK, M.; MCKEE IRGWIN, R. (coord.) Diccionario de estudios culturales latinoamericanos. México: Instituto Mora/Siglo XXI, 2009.

URONDO RABOY, A. ¿Quién te creés que sos? Buenos Aires: Capital Intelectual, 2012.

VILCHES, V. De (s) madres o el rastro materno en las escrituras del yo. Santiago: Cuarto Propio, 2003.

\section{Recebido em: 15/09/2016 Aceito em: 16/11/2016}

Referência eletrônica: PELLER, Mariela. Lugar de hija, lugar de madre. Autoficción y legados familiares en la narrativa de hijas de desaparecidos en Argentina. Criação E Crítica, n. 17, p.75-90, dez. 2016. Disponível em: 〈http://revistas.usp.br/criacaoecritica〉. Acesso em: dd mmm. aaaa. 